\title{
Improvement of Waste Tire Pyrolysis Oil and Performance Test with Diesel in CI Engine
}

\author{
M. N. Islam and M. R. Nahian \\ Department of Mechanical Engineering, Rajshahi University of Engineering \& Technology, Rajshahi, Bangladesh \\ Correspondence should be addressed to M. N. Islam; nurul50.ruet@gmail.com
}

Received 2 May 2016; Revised 19 July 2016; Accepted 2 August 2016

Academic Editor: Wei-Hsin Chen

Copyright ( 2016 M. N. Islam and M. R. Nahian. This is an open access article distributed under the Creative Commons Attribution License, which permits unrestricted use, distribution, and reproduction in any medium, provided the original work is properly cited.

\begin{abstract}
The standard of living, quality of life, and development of a nation depend on its per capita energy consumption. Global energy supply that mainly depends on fossil fuel is decreasing day by day. It is estimated that the energy demand will be increased five times by the year 2021 from present scenario. Due to the fossil fuel crisis, the development of alternative fuel technologies has drawn more attraction to deliver the replacement of fossil fuel. Pyrolysis is one of the promising alternative fuel technologies which produces valuable oil, char, and gas product from organic waste. Early investigations report that tire pyrolysis oil extracted from vacuum pyrolysis method seemed to have properties similar to diesel fuel. The main concern of this paper is to produce and improve the properties of crude tire pyrolysis oil by desulfurizing, distilling, and utilizing it with diesel in CI engine to analyze the efficiency for various compositions.
\end{abstract}

\section{Introduction}

Approximately 1.5 billion tires are produced each year which will eventually enter the waste stream representing a major potential waste and environmental problem [1]. In Bangladesh, total waste tire generation of each year is about 90000 tons [2]. Vehicle tires contain long chain polymer (butadiene, isoprene, and styrene-butadiene) which cross-linked with sulfur thus having excessive resistance to degradation. One common way for disposal of these waste tires is land filling. Tires are bulky, and $75 \%$ of the space a tire occupies is void, so the land filling of waste tires has several difficulties [3]. Waste tire needs a considerable amount of space because of the volume of tires cannot be compacted. Tires tend to float or rise in a landfill and come to the surface. Under the ground, the void space of waste tires captures various gases such as methane which has a tendency to burn suddenly with a vast explosion. If the waste tire is scattered on land in vain then it comes with rain water and may be a good place for breeding mosquitoes or others bacterias. This causes various harmful diseases to human beings. If the scrap tires burn directly in brick fields or any other incineration plant then various harmful gases such as $\mathrm{CO}_{2}, \mathrm{CO}, \mathrm{SO}_{x}$, and $\mathrm{NO}_{x}$ will be produced which cause environmental pollution. On the other hand, burning of these tires causes excessive damage to human health caused by the pollutant emissions such as polyaromatic hydrocarbons (PAHs), benzene, styrene, butadiene, and phenol-like substances [4]. Conversion of these waste tires to energy through pyrolysis is one of the recent technologies in minimizing not only the waste disposal but also utilizing as an alternative fuel for internal combustion engines. Pyrolysis is generally described as the thermal decomposition of the organic wastes in the absence of oxygen at mediate temperature about $450^{\circ} \mathrm{C}$ [5]. The advantage of pyrolysis process is its ability to handle waste tire. It was reported that pyrolysis oil of automobile tires contains $85.54 \% \mathrm{C}, 11.28 \% \mathrm{H}, 1.92 \% \mathrm{O}, 0.84 \% \mathrm{~S}$, and $0.42 \% \mathrm{~N}$ components [6]. Pyrolysis process is also nontoxic and there is no emission of harmful gas unlike incineration [7]. Tire pyrolysis oil has been found to have a high gross calorific value of around (41-44) MJ/Kg. It would encourage their use as replacement for diesel fuel if it is properly distilled [8]. Therefore, these waste tires should be utilized by converting to new and clean energies. 


\section{Literature Review}

The disposal of used tires from automotive vehicles becomes inexhaustible. Though many disposal methods are available to dispose of the waste automobile tires, still the problem persists. Pyrolysis of a substance offers value added products such as pyrolysis oil, pyrolysis gas, and char. It is also reported that TPO has properties similar to those of diesel fuel. One common way of disposal for these waste tires is land filling. It was surveyed that tires are bulky, and $75 \%$ of the space a tire occupies is void, so the land filling of waste tires has several difficulties [3].

In this study, a batch type fixed bed fire tube heating pyrolysis system has been designed and fabricated for liquid production from scrap tires of rickshaws, bicycles, and trucks. The scrap tires were pyrolysed in an internally heated batch type fixed bed fire tube heating reactor system. The products were liquid, char, and gases. The maximum liquid and char yield was 52 and $35 \mathrm{wt} \%$, for bicycle and rickshaw, respectively. For truck tires, the liquid and char yield was maximum 60 and $23 \mathrm{wt} \%$, respectively. The heat value of liquid of rickshaw and truck tires was found of 41 and 40.7 MJ/kg, respectively [9].

Aydin and Ilkiliç [10] carried out optimizing the fuel production from waste vehicle tires by pyrolysis and resembling diesel fuel by various desulfurization methods. On that study, in order to reduce the high sulfur content of the fuel, $\mathrm{CaO}$, $\mathrm{Ca}(\mathrm{OH})_{2}$, and $\mathrm{NaOH}$ catalysts were used. In addition, effects of variables such as temperature, the catalyst ratio, and the $\mathrm{N}_{2}$ flow rate on yield were investigated. The sulfur content of the product was found to be $34.25 \%$ lower with the utilization of $5 \% \mathrm{Ca}(\mathrm{OH})_{2}$ in the reaction. In order to make the sulfur content of the product closer diesel fuel, the acetic acid$\mathrm{H}_{2} \mathrm{O}_{2}$, formic acid $-\mathrm{H}_{2} \mathrm{O}_{2}$, and $\mathrm{H}_{2} \mathrm{SO}_{4}$ were used in different proportions. It was found that the density and sulfur content of low sulfur tire fuel were slightly higher than that of diesel fuel, but other features and distillation curves were very close to diesel fuel.

A work on the fuel properties of pyrolysis liquid derived from urban solid wastes in Bangladesh was carried out by Conesa et al. [11]. Through the experimental investigation it is found that the optimum reaction condition for scrap tire pyrolysis was at reactor bed temperature of $450^{\circ} \mathrm{C}$, for feedstock size of $2-3 \mathrm{~cm}$ with a running time of $75 \mathrm{~min}$. At this condition, the liquid yield was $64 \mathrm{wt} \%$ of the solid scrap tire feed.

A work on the pyrolysis of sugarcane bagasse for liquid fuel production was carried out by Islam et al. [12]. Through the experiment investigation it is found that a reactor bed temperature of $450^{\circ} \mathrm{C}$ for a feed particle size of (300-600) $\mu \mathrm{m}$ and at a gas flow rate of 4 liter/minute, an oil yield of $49 \mathrm{wt} \%$ of dry feed was obtained.

Murgan et al. [13] carried out evaluating the performance and emission characteristics of a single cylinder direct injection diesel engine fueled by 10,30 , and 50 percent blends of tire pyrolysis oil (TPO) with diesel fuel (DF). Results showed that the brake thermal efficiency of the engine fueled by TPODF blends increased with increase in blend concentration and higher than diesel. $\mathrm{NO}_{x}, \mathrm{HC}, \mathrm{CO}$, and smoke emissions

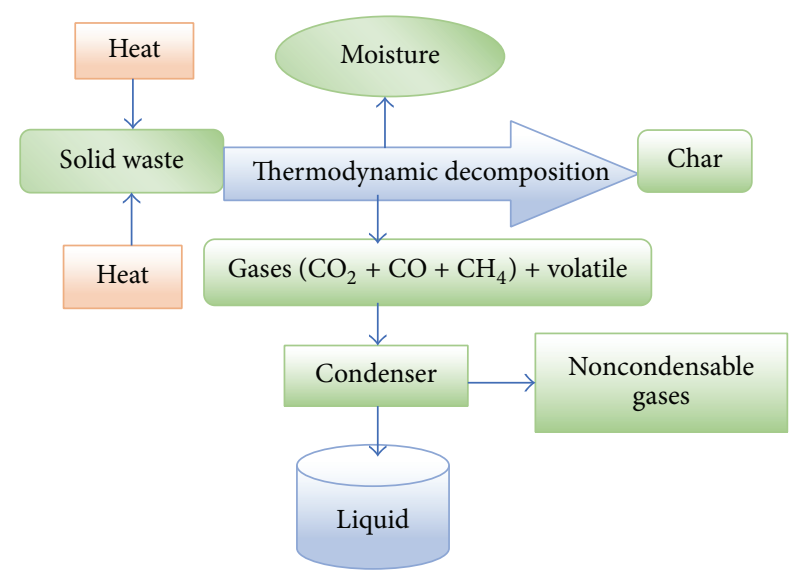

FIGURE 1: Steps of pyrolysis process.

were found to be higher at higher loads due to high aromatic content and longer ignition delay.

de Marco Rodriguez et al. [14] studied the behavior and chemical analysis of tire pyrolysis oil. In this work, it is reported that tire oil is a complex mixture of organic compounds of 5-20 carbons with a higher proportion of aromatics. The percentage of aromatics, aliphatic, nitrogenated compounds, and benzothiazole were also determined in the tire pyrolysis oil at various operating temperatures of the pyrolysis process. Aromatics were found to be about $34.7 \%$ to $75.6 \%$ when the operating temperature was varied between $300^{\circ} \mathrm{C}$ and $700^{\circ} \mathrm{C}$, while aliphatics were about $19.8 \%$ to $59.2 \%$.

Al-Lal et al. [15] carried out their research on desulfurization of pyrolysis fuels obtained from waste. In this work, they used two affordable desulfurization techniques without hydrogen to reduce the sulfur content of these three pyrolysis fuels with moderate success that could make them useful as heating fuels. These desulfurization methods are based on the oxidation of the sulfur compounds present in these fuels with hydrogen peroxide to more polar sulfur compounds like sulfoxides and sulfones that can be later eliminated by methanol extraction or silica gel adsorption. The desulfurization rate was $64 \%$.

\section{Material and Method}

At first, automobile tires are cut into a number of pieces and the bead, steel wires, and fabrics are removed. The tire chips are washed, dried, and fed in a mild steel fixed bed reactor unit. The steps of pyrolysis process are shown in Figure 1.

The feedstock is externally heated up in the reactor in absence of oxygen. The pyrolysis reactor design for the experiment is a cylindrical chamber of inner diameter $110 \mathrm{~mm}$, outer diameter $115 \mathrm{~mm}$, and height $300 \mathrm{~mm}$ which is fully insulated. $2 \mathrm{~kW}$ of power is supplied to the reactor for external heating. The temperature of the reactor is controlled by a temperature controller. The process is carried out at $450-650^{\circ} \mathrm{C}$. The heating rate is maintained at $5 \mathrm{~K} / \mathrm{min}$. The residence time of the feedstock in the reactor is 120 minutes. The products of pyrolysis in the form of vapour are sent to a 
TABLE 1: Percentage of pyrolysis products.

\begin{tabular}{lcccc}
\hline $\begin{array}{l}\text { Pyrolysis } \\
\text { products }\end{array}$ & $\begin{array}{c}\text { Tire pyrolysis } \\
\text { oil }\end{array}$ & Char & Pyro gas & Moisture \\
\hline $\begin{array}{l}\text { Percentage } \\
(\%)\end{array}$ & 55 & 34 & 10 & 1 \\
\hline
\end{tabular}

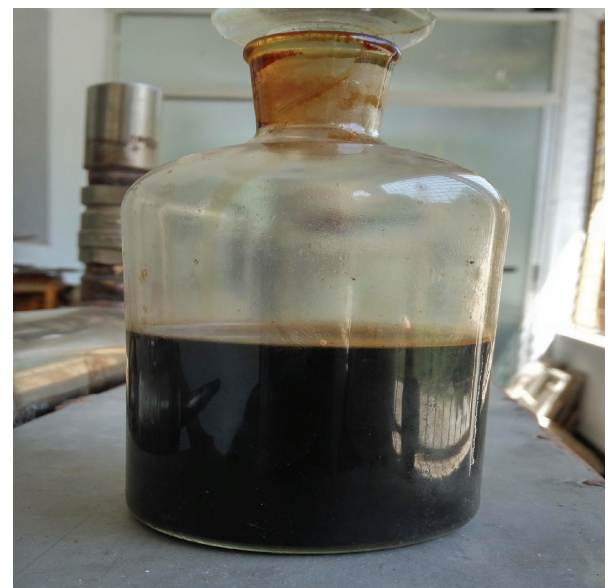

FIGURE 2: Crude tire pyrolysis oil from waste tire.

water cooled condenser and the condensed liquid is collected as fuel. Three products are obtained in the pyrolysis, namely, tire pyrolysis oil (TPO), pyro gas, and char. $1.9 \mathrm{~kg}$ of feedstock is used to produce $1 \mathrm{~kg}$ of tire pyrolysis oil. The heat energy required for pyrolysis process per $\mathrm{kg}$ of TPO produced is around $6 \mathrm{MJ} / \mathrm{kg}$ [14]. The percentages of pyrolysis products are given in Table 1 . oil.

Figure 2 shows the physical view of crude tire pyrolysis

\section{Improvement of Crude Tire Pyrolysis Oil (TPO)}

The improvement of crude TPO involves three stages:
(A) Removal of moisture.
(B) Desulfurization.
(C) Distillation.

4.1. Removal of Moisture. Initially crude TPO is heated up to $100^{\circ} \mathrm{C}$, in a cylindrical vessel for a particular period to remove the moisture, before subjecting it to any further chemical treatment.

4.2. Desulfurization. The moisture-free crude TPO contains impurities, carbon particles, and sulfur particles. A known volume of concentric hydrosulfuric acid (8\%) is mixed with the crude TPO and stirred well. The mixture is kept for about 40 hours. After 40 hours, the mixture is found to be in two layers. The top layer is a thin mixture and the bottom layer is thick sludge. The top layer is taken for atmospheric distillation and the sludge is removed and disposed of. In

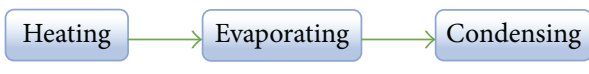

Figure 3: Sequence of distillation process.

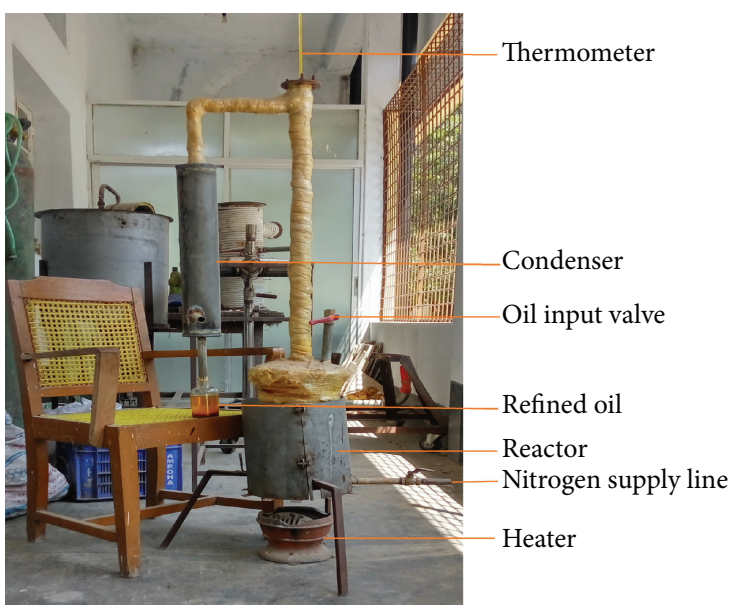

FIGURE 4: Experimental setup of the distillation plant.

the desulfurization process, the efficiency of sulfur removal is $61.6 \%$.

4.3. Distillation. Distillation is a commonly used method for purifying liquids and separating mixtures of liquids into their individual components. The distillation process is shown in Figure 3.

Atmospheric distillation process is carried out to separate the lighter and heavier fraction of hydrocarbon oil. A known sample of chemically treated crude TPO is taken for vacuum distillation process. The sample is externally heated in a closed chamber by electric heater of $1.5 \mathrm{~kW}$. The vapour leaving the chamber is condensed in a water condenser and the distilled tire pyrolysis oil (DTPO) is collected separately. Noncondensable volatile vapours are left to the atmosphere. The distillation is carried out at $150-200^{\circ} \mathrm{C}$ because the maximum amount of DTPO is obtained within this range. Nitrogen gas is supplied to carry out producer gas from the reactor to the condenser and also create inert environment to the reactor. $80 \%$ of TPO is distilled in the distillation whereas $5 \%$ of TPO is left out as pyro gas and $15 \%$ is found as sludge. Figure 4 shows the experimental setup of distillation plant.

The DTPO has irritating odor like acid smell. The odor can be reduced with the help of adding some masking agents or odor removal agents. Figure 5 shows the physical view of distilled tire pyrolysis oil (DTPO). Figure 5 shows the physical view of distilled tire pyrolysis oil.

The properties of tire pyrolysis oil (TPO), distilled tire pyrolysis oil (DTPO), and diesel fuel are shown in Table 2.

\section{Results and Discussion}

5.1. Distillation Process Analysis. Figures 6 and 7 shows that the crude pyrolysis oil began to distill in $18 \mathrm{~min}$ at $77^{\circ} \mathrm{C}$ and ended in $110 \mathrm{~min}$ at $184^{\circ} \mathrm{C}$. The highest amount of oil was 
TABle 2: Properties of TPO, DTPO, and diesel fuel.

\begin{tabular}{lccc}
\hline Properties & Tire pyrolysis oil & Distilled tire pyrolysis oil & Diesel fuel \\
\hline Density at $15^{\circ} \mathrm{C}, \mathrm{kg} / \mathrm{L}$ & 0.9563 & 0.8355 & $0.8200-0.8600$ \\
Kinematic viscosity at $40^{\circ} \mathrm{C}$, cst & 16.39 & 0.89 & 2.00 \\
Pour point, ${ }^{\circ} \mathrm{C}$ & -3.00 & Below -6.00 & -42 to -30 \\
Flash point, ${ }^{\circ} \mathrm{C}$ & 50.00 & Below 10.00 & Above 55 \\
Gross calorific value, $\mathrm{MJ} / \mathrm{kg}$ & 42.00 & 43.56 & $44.00-46.00$ \\
$\mathrm{C}(\mathrm{wt} \%)$ & 85.67 & 87 & 87 \\
$\mathrm{H}(\mathrm{wt} \%)$ & 10.04 & 10.37 & 12.71 \\
$\mathrm{O}(\mathrm{wt} \%)$ & 2.02 & 0.84 & nil \\
$\mathrm{S}(\mathrm{wt} \%)$ & 1.12 & 0.43 & 0.16 \\
$\mathrm{~N}(\mathrm{wt} \%)$ & 1.15 & 1.36 & 0.13 \\
\hline
\end{tabular}

TABLE 3: Experimental data for distilled oil procurement at different temperature.

\begin{tabular}{lccc}
\hline Time $(\mathrm{min})$ & Temperature of the reactor $\left({ }^{\circ} \mathrm{C}\right)$ & Amount of oil received $(\mathrm{mL})$ & Total amount of oil received $(\mathrm{mL})$ \\
\hline 0 & 30 & 0 & 0 \\
10 & 58 & 0 & 0 \\
20 & 80 & 35 & 35 \\
30 & 98 & 80 & 115 \\
40 & 110 & 120 & 235 \\
50 & 123 & 175 & 410 \\
60 & 146 & 240 & 650 \\
70 & 160 & 270 & 920 \\
80 & 170 & 320 & 1240 \\
90 & 174 & 395 & 1635 \\
100 & 178 & 260 & 1985 \\
110 & 184 & 190 & 2090 \\
120 & 188 & 60 & 2150 \\
130 & 192 & 0 & 2150 \\
\hline
\end{tabular}

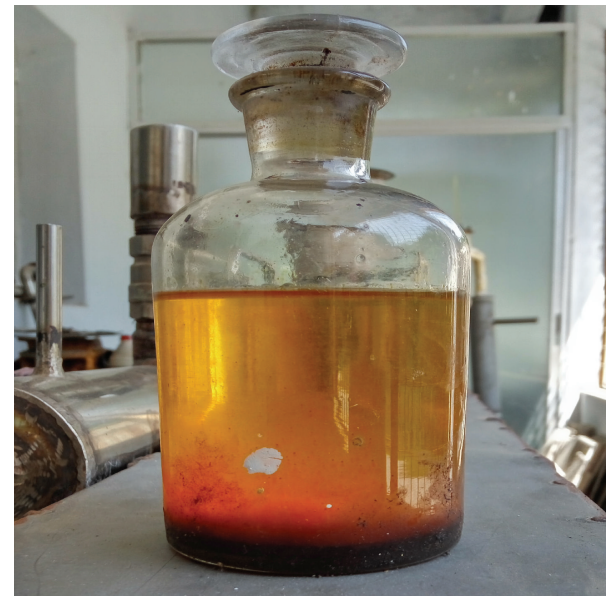

FIGURE 5: Distilled tire pyrolysis oil.

obtained in $90 \mathrm{~min}$ at $174^{\circ} \mathrm{C}$. After that temperature, the amount of received oil is decreasing and stopped at $184^{\circ} \mathrm{C}$. After distillation, DTPO obtained $53.75 \%$ of the total crude TPO (Table 3).

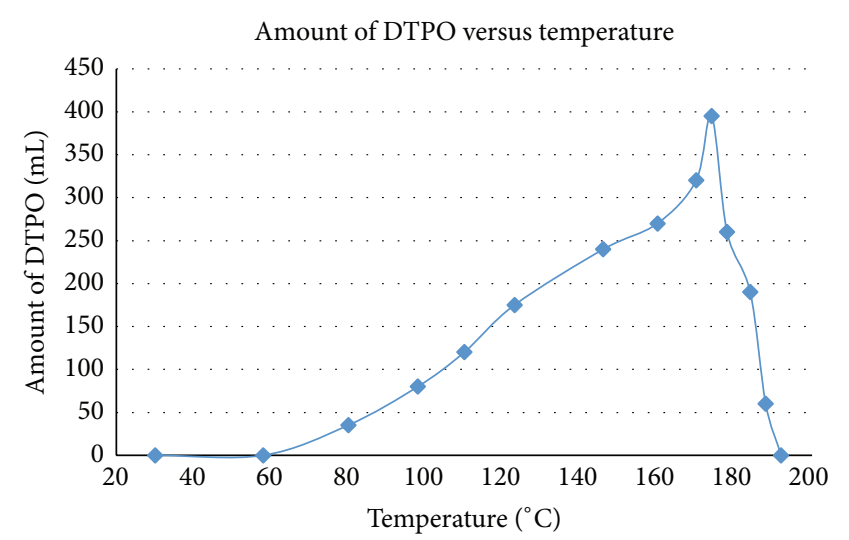

FIGURE 6: Graphical representation of amount of oil received with different temperature.

5.2. Performance Test of Distilled Tire Pyrolysis Oil (DTPO). Engine performance indicates the effect of a fuel in the engine. It shows the trend and possibility of using distilled tire pyrolysis oil to replace diesel fuel without any engine modifications [16]. It is necessary to determine engine brake power, brake specific fuel consumption, and brake thermal 


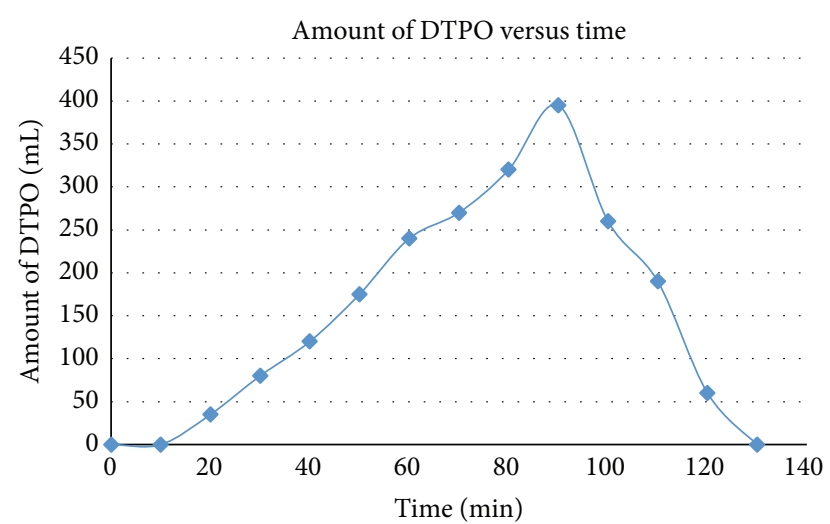

FIGURE 7: Graphical representation of amount of oil received with different time.

TABLE 4: Engine specifications.

\begin{tabular}{lc}
\hline Engine type & 4-stroke CI engine \\
Cooling & Water cooling \\
Speed & $1500 \mathrm{rpm}$ \\
Rated power & $7.5 \mathrm{HP}$ \\
\hline
\end{tabular}

efficiency. The performance parameters can be calculated by following equations [17].

5.2.1. Engine Brake Power. Engine brake power $(P)$ is delivered by engine and absorbed load. It is the product of torque and angular engine speed where $P$ is engine brake power in $\mathrm{kW} ; N$ is angular speed of the engine in rpm as

$$
P=\frac{2 \pi N T}{60 \times 1000} .
$$

5.2.2. Brake Specific Fuel Consumption. Brake specific fuel consumption (BSFC) is the comparison of engine to show the efficiency of the engine against fuel consumption of the engine in $\mathrm{kg} / \mathrm{kWhr}$ where $\left(m_{f}\right)$ is the fuel consumption rate in $\mathrm{kg} / \mathrm{hr}$ as

$$
\mathrm{BSFC}=\frac{\text { Fuel consumption rate }}{\text { Engine brake power }} .
$$

5.2.3. Brake Thermal Efficiency. The percentage of brake thermal efficiency of the engine is related to engine brake power and total energy input to the engine.

The quality of the blended DTPO with diesel fuel is tested in Beco diesel engine. The engine is kept fixed at 27\% part load. The specifications of the engine are shown in Table 4.

DTPO has about $7 \%$ higher heating value than crude TPO. This is due to the elimination of the impurities, moisture, carbon particles, sulfur, and sediments. Four test fuels have been taken for the performance test. These are $100 \%$ diesel fuel, $75 \%$ diesel with $25 \%$ distilled pyrolysis oil (DTPO 25), 50\% diesel fuel with 50\% distilled pyrolysis oil (DTPO 50), and $25 \%$ diesel with $75 \%$ distilled pyrolysis oil (DTPO 75) (Table 5).

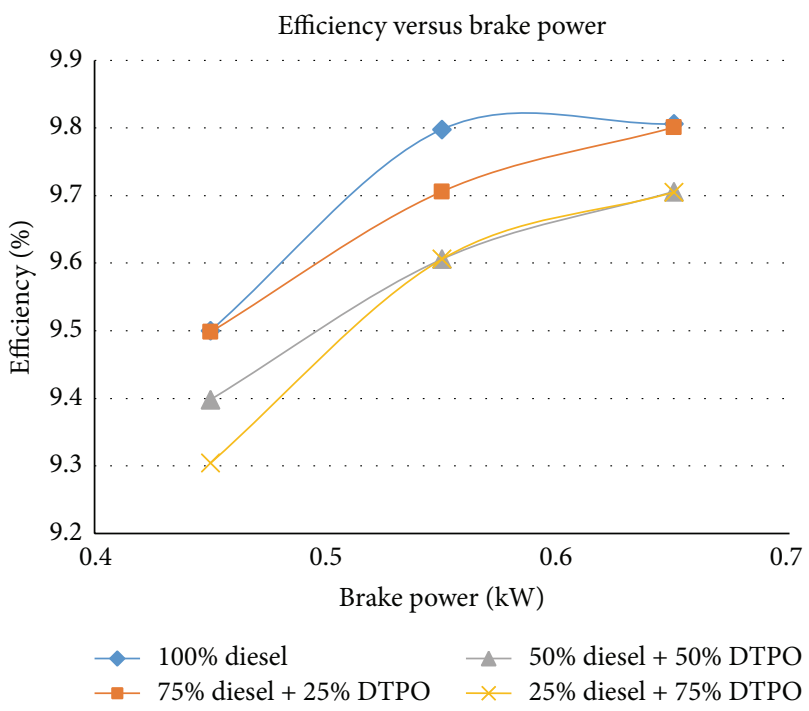

Figure 8: Variation of efficiency with respect to brake power at $27 \%$ part load.

The graphical representation of performance of the engine with neat diesel and DTPO blends is described in Figures $8,9,10$, and 11 .

Figure 8 shows the comparison of the brake thermal efficiency with brake power for the tested fuels at $27 \%$ part load. It can be observed from the figure that, at $0.45 \mathrm{~kW}$, the thermal efficiency is $9.5 \%$ for DF whereas for blending of $25 \%$ DTPO, $50 \%$ DTPO, and 75\% DTPO with diesel it is $9.498 \%$, $9.398 \%$, and $9.304 \%$, respectively. The thermal efficiencies of DTPO-DF blends are lower compared to DF. Reduction in thermal efficiency by about $0.0212 \%, 1.07 \%$, and $2.06 \%$ for blending of 25\% DTPO, 50\% DTPO, and 75\% DTPO with diesel compared to diesel occurred.

At $0.55 \mathrm{~kW}$, the thermal efficiency is $9.798 \%$ for DF whereas for blending of $25 \%$ DTPO, 50\% DTPO, and $75 \%$ DTPO with diesel it is $9.706 \%, 9.698 \%$, and $9.606 \%$, respectively. Reduction in thermal efficiency by about $0.938 \%$, $1.02 \%$, and $1.94 \%$ for blending of $25 \%$ DTPO, $50 \%$ DTPO, and 75\% DTPO with diesel compared to diesel occurred.

At $0.65 \mathrm{~kW}$, the thermal efficiency is $9.806 \%$ for DF whereas for blending of $25 \%$ DTPO, 50\% DTPO, and $75 \%$ DTPO with diesel it is $9.801 \%, 9.707 \%$, and $9.7046 \%$, respectively. Reduction in thermal efficiency by about $0.05 \%$, $1.009 \%$, and $1.034 \%$ for blending of 25\% DTPO, 50\% DTPO, and $75 \%$ DTPO with diesel compared to diesel occurred.

Figure 9 shows the comparison of the BSFC with brake power for the tested fuels at $27 \%$ part load. It can be observed from the figure that BSFC increases with increase in the concentration of DTPO in DTPO-DF blend. It can be observed from the figure that, at $0.45 \mathrm{~kW}$, the BSFC is 0.852 for DF whereas for blending of 25\% DTPO, 50\% DTPO, and 75\% DTPO with diesel it is $0.8524,0.862$, and 0.866 , respectively. The BSFC of DTPO-DF blends are higher compared to DF. Increase in BSFC by about $0.046 \%, 1.17 \%$, and $1.64 \%$ for blending of 25\% DTPO, 50\% DTPO, and 75\% DTPO with diesel compared to diesel occurred. 
TABle 5: Performance results for different blended fuels.

\begin{tabular}{lccc}
\hline Fuel & Brake power $(\mathrm{kW})$ & Efficiency (\%) & Brake specific fuel consumption, kg/kWhr \\
\hline \multirow{2}{*}{$100 \%$ diesel } & 0.45 & 9.500 & 0.852 \\
& 0.55 & 9.798 & 0.827 \\
\hline \multirow{2}{*}{$75 \%$ diesel + 25\% DTPO } & 0.65 & 9.806 & 0.820 \\
& 0.45 & 9.498 & 0.852 \\
\hline & 0.55 & 9.706 & 0.829 \\
$50 \%$ diesel + 50\% DTPO & 0.65 & 9.801 & 0.824 \\
& 0.45 & 9.398 & 0.862 \\
& 0.55 & 9.606 & 0.836 \\
$25 \%$ diesel + 75\% DTPO & 0.65 & 9.707 & 0.828 \\
& 0.45 & 9.304 & 0.866 \\
\hline
\end{tabular}

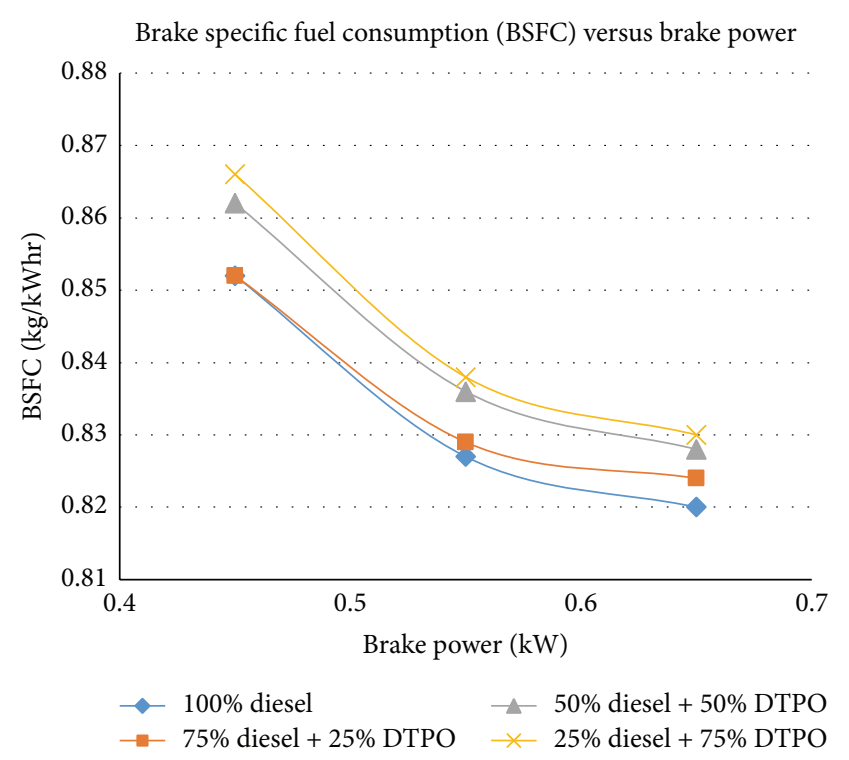

FIGURE 9: Variation of BSFC with respect to brake power at 27\% part load.

At $0.55 \mathrm{~kW}$, the BSFC is 0.827 for DF whereas for blending of 25\% DTPO, 50\% DTPO, and 75\% DTPO with diesel it is $0.829,0.836$, and 0.838 , respectively. Increase in BSFC by about $0.24 \%, 1.08 \%$, and $1.33 \%$ for blending of $25 \%$ DTPO, $50 \%$ DTPO, and 75\% DTPO with diesel compared to diesel occurred.

At $0.65 \mathrm{~kW}$, the BSFC is 0.82 for DF whereas for blending of 25\% DTPO, 50\% DTPO, and 75\% DTPO with diesel it is $0.824,0.828$, and 0.83 , respectively. Increase in BSFC by about $0.487 \%, 0.975 \%$, and $1.21 \%$ for blending of $25 \%$ DTPO, $50 \%$ DTPO, and 75\% DTPO with diesel compared to diesel. This behavior is obvious since the engine will consume more fuel with DTPO-DF blends than DF, to gain the same power output owing to the lower heating value of DTPO-DF blends (Table 6).

Figure 10 shows the comparison of the brake thermal efficiency with engine speed for the tested fuels at $27 \%$ load. It can be observed from the figure that, at $950 \mathrm{rpm}$, the

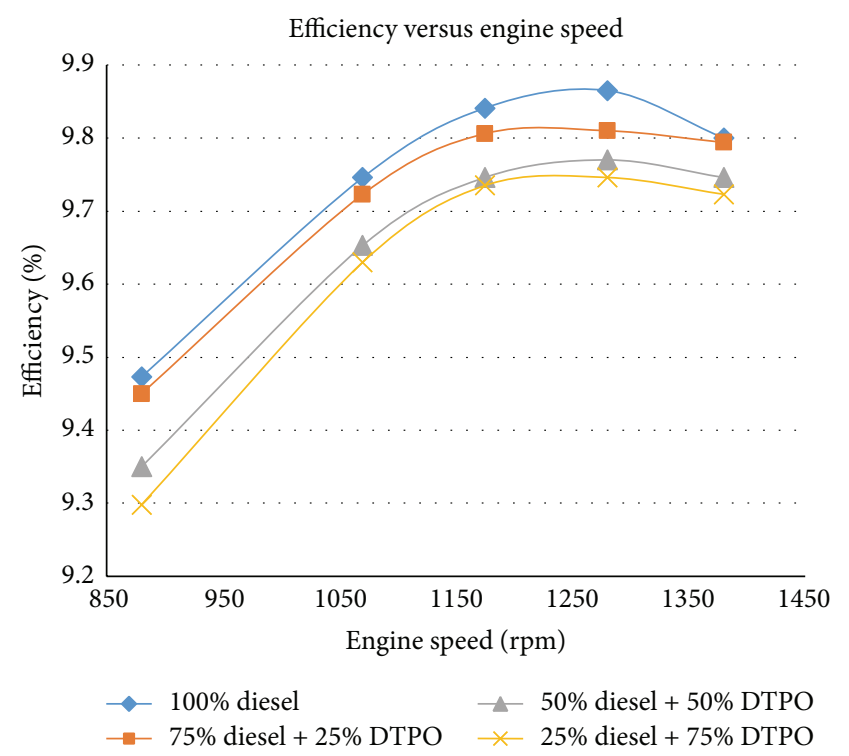

Figure 10: Variation of efficiency with respect to engine speed at $27 \%$ part load.

thermal efficiency is $9.598 \%$ at $22.24 \mathrm{~N}$ load for DF whereas for blending of 25\% DTPO, 50\% DTPO, and 75\% DTPO with diesel it is $9.506 \%, 9.406 \%$, and $9.403 \%$, respectively. The thermal efficiencies of DTPO-DF blends are lower compared to DF.

Reduction in thermal efficiency by about $0.958 \%, 2 \%$, and $2.03 \%$ for blending of $25 \%$ DTPO, $50 \%$ DTPO, and $75 \%$ DTPO with diesel compared to diesel occurred.

At $1150 \mathrm{rpm}$, the thermal efficiency is $9.802 \%$ for DF whereas for blending of 25\% DTPO, 50\% DTPO, and $75 \%$ DTPO with diesel it is $9.798 \%, 9.703 \%$, and $9.702 \%$, respectively. Reduction in thermal efficiency by about $0.04 \%$, $1.009 \%$, and $1.02 \%$ for blending of $25 \%$ DTPO, 50\% DTPO, and $75 \%$ DTPO with diesel compared to diesel occurred.

At $1350 \mathrm{rpm}$, the thermal efficiency is $9.802 \%$ for DF whereas for blending of 25\% DTPO, 50\% DTPO, and $75 \%$ DTPO with diesel it is $9.798 \%, 9.706 \%$, and $9.704 \%$, 
TABLE 6: Performance test of Beco diesel engine by using 100\%, 75\%, $50 \%$, and $25 \%$ diesel fuel at $27 \%$ part load.

\begin{tabular}{lccc}
\hline Fuel & $\begin{array}{c}\text { Engine speed } \\
(\mathrm{rpm})\end{array}$ & $\begin{array}{c}\text { Efficiency } \\
(\%)\end{array}$ & $\begin{array}{c}\text { BSFC } \\
(\mathrm{kg} / \mathrm{kWh})\end{array}$ \\
\hline & 880 & 9.473 & 0.854 \\
$100 \%$ diesel & 1070 & 9.746 & 0.830 \\
& 1175 & 9.841 & 0.822 \\
& 1280 & 9.865 & 0.820 \\
& 1380 & 9.800 & 0.825 \\
\hline $75 \%$ diesel + 25\% DTPO & 880 & 9.450 & 0.856 \\
& 1070 & 9.723 & 0.832 \\
& 1175 & 9.806 & 0.825 \\
& 1280 & 9.810 & 0.824 \\
& 1380 & 9.794 & 0.826 \\
\hline & 880 & 9.350 & 0.865 \\
& 1070 & 9.653 & 0.838 \\
& 1175 & 9.746 & 0.830 \\
& 1280 & 9.770 & 0.828 \\
& 1380 & 9.746 & 0.830 \\
\hline & 880 & 9.298 & 0.870 \\
& 1070 & 9.630 & 0.840 \\
& 1175 & 9.735 & 0.831 \\
& 1280 & 9.746 & 0.830 \\
& 1380 & 9.723 & 0.832 \\
\hline
\end{tabular}

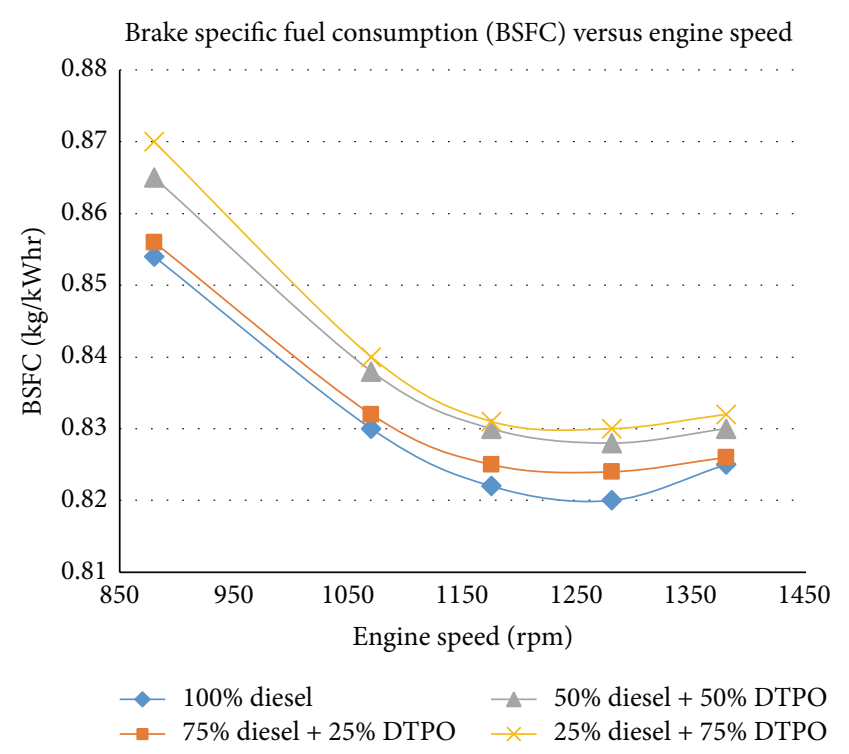

FIGURE 11: Variation of BSFC with respect to engine speed at $27 \%$ part load.

respectively. Reduction in thermal efficiency by about $0.04 \%$, $0.979 \%$, and $0.99 \%$ for blending of $25 \%$ DTPO, $50 \%$ DTPO, and $75 \%$ DTPO with diesel compared to diesel occurred.

Figure 11 shows the comparison of the BSFC with engine speed for the tested fuels at $27 \%$ part load. It can be observed from the figure that BSFC increases with increase in the concentration of DTPO in DTPO-DF blend. It can be observed from the figure that, at $950 \mathrm{rpm}$, the BSFC is 0.845 for DF whereas for blending of $25 \%$ DTPO, 50\% DTPO, and $75 \%$ DTPO with diesel, it is $0.846,0.855$, and 0.858 , respectively. The BSFC of DTPO-DF blends are higher compared to DF. Increase in BSFC by about $0.118 \%, 1.18 \%$, and $1.53 \%$ for blending of 25\% DTPO, 50\% DTPO, and 75\% DTPO with diesel compared to diesel occurred.

At $1150 \mathrm{rpm}$, the BSFC is 0.82345 for DF whereas for blending of 25\% DTPO, 50\% DTPO, and 75\% DTPO with diesel it is $0.826,0.831$, and 0.832 , respectively. Increase in BSFC by about $0.315 \%, 0.92 \%$, and $1.04 \%$ for blending of $25 \%$ DTPO, 50\% DTPO, and 75\% DTPO with diesel compared to diesel occurred.

At $1350 \mathrm{rpm}$, the $\mathrm{BSFC}$ is 0.8236 for DF whereas for blending of 25\% DTPO, 50\% DTPO, and 75\% DTPO with diesel it is $0.8256,0.8296$, and 0.8316 , respectively. Increase in BSFC by about $0.33 \%, 0.40 \%$, and $70 \%$ for blending of $25 \%$ DTPO, 50\% DTPO, and 75\% DTPO with diesel compared to diesel occurred.

The engine exhaust gas temperature for DTPO varies from $119^{\circ} \mathrm{C}$ at low load to $305^{\circ} \mathrm{C}$ at full load and in case of pure diesel oil varies from $119^{\circ} \mathrm{C}$ at low load to $312^{\circ} \mathrm{C}$ at full load. During emission, the pollutants are hydrocarbons (HC), carbon dioxide $\left(\mathrm{CO}_{2}\right)$, carbon monoxide $(\mathrm{CO})$, nitrogen oxides $\left(\mathrm{NO}_{x}\right)$, and sulfur oxides $\left(\mathrm{SO}_{x}\right)$. The DTPO is likely higher than diesel oil as fuel with higher aromatics exhibits higher $\mathrm{NO}_{x}, \mathrm{SO}_{x}$, and smoke at full load.

\section{Conclusion}

In the presented study, it is found that the distilled tire pyrolysis oil is similar to diesel fuel and able to replace diesel fuel in small engine. Blends of DTPO 25 give better results than DTPO 50 and DTPO 75 . The following are the conclusions based on the experimental results obtained while operating single cylinder diesel engine with DTPO blends:

(I) DTPO 25 blends can be directly utilized in diesel engine without any engine modification.

(II) The brake thermal efficiency of DTPO 25 is slightly lower than diesel fuel. But for DTPO 50 and DTPO 75 it is much lower compared to diesel fuel.

(III) Brake specific fuel consumption of DTPO 25 blend is very close to the specific fuel consumption of diesel. But for DTPO 50 and DTPO 75 it is slightly higher.

So it is advisable not to use DTPO 50 and DTPO 75 in CI engines.

\section{Competing Interests}

The authors declare that they have no competing interests.

\section{References}

[1] P. T. Williams, "Pyrolysis of waste tyres: a review," Waste Management, vol. 33, no. 8, pp. 1714-1728, 2013. 
[2] Bangladesh Bureau of Statistics and Government of Peoples Republic of Bangladesh, Statistical Year Book of Bangladesh, 24th edition, 2008.

[3] I. M. Rodriguez, M. F. Laresgoiti, M. A. Cabrero, A. Torres, M. J. Chomón, and B. M. Caballero, "Pyrolysis of scrap tyres," Fuel Processing Technology, vol. 72, no. 1, pp. 9-22, 2001.

[4] J. I. Reisman, "Air emissions from scrap tire combustion," Tech. Rep. EPA-600/R-97-115, 1997.

[5] P. T. Williams and S. Besler, "Pyrolysis-thermogravimetric analysis of tyres and tyre components," Fuel, vol. 74, no. 9, pp. 1277-1283, 1995.

[6] A. M. Mastral, R. Murillo, M. S. Callen, and T. Garcia, "Optimisation of scrap automotive tyres recycling into valuable liquid fuels," Resources, Conservation and Recycling, vol. 29, no. 4, pp. 263-272, 2000.

[7] J. Scheirs and W. Kaminsky, Feedstock Recycling and Pyrolysis of Waste Pastic: Converting Waste Plastics into Diesel and Other Fuels, John Wiley \& Sons, Chichester, UK, 2006.

[8] M. R. Islam, H. Haniu, and R. A. Beg, "Liquid fuels and chemicals from pyrolysis of motorcycle tire waste: product yields, compositions and related properties," Fuel, vol. 87, no. 13-14, pp. 3112-3122, 2008.

[9] M. S. I. Jehadi, Design fabrication and performance study of a batch type fixed bed fire tube heating pyrolysis system [B.Sc. Engineering thesis], Department of Mechanical Engineering, RUET, Rajshahi, Bangladesh, 2003-2004.

[10] H. Aydin and C. Ilkiliç, "Optimization of fuel production from waste vehicle tires by pyrolysis and resembling to diesel fuel by various desulfurization methods," Fuel, vol. 102, pp. 605-612, 2012.

[11] J. A. Conesa, I. Martín-Gullón, R. Font, and J. Jauhiainen, "Complete study of the pyrolysis and gasification of scrap tires in a pilot plant reactor," Environmental Science and Technology, vol. 38, no. 11, pp. 3189-3194, 2004.

[12] M. N. Islam, M. N. Islam, and M. R. A. Beg, "The fuel properties of pyrolysis liquid derived from urban solid wastes in Bangladesh," Bioresource Technology, vol. 92, no. 2, pp. 181186, 2004.

[13] S. Murgan, M. Ramaswamy, and C. Nagaranja, "The use of tyre pyrolysis oil in diesel engines," Waste Management, vol. 28, no. 12, pp. 2743-2749, 2008.

[14] I. de Marco Rodriguez, M. F. Laresgoiti, M. A. Cabrero, A. Torres, M. J. Chomón, and B. Caballero, "Pyrolysis of scrap tyres," Fuel Processing Technology, vol. 72, no. 1, pp. 9-22, 2001.

[15] A.-M. Al-Lal, D. Bolonio, A. Llamas, M. Lapuerta, and L. Canoira, "Desulfurization of pyrolysis fuels obtained from waste: lube oils, tires and plastics," Fuel, vol. 150, pp. 208-216, 2015.

[16] C. Wongkhorsub and N. Chindaprasert, "A comparison of the use of pyrolysis oils in diesel engine," Energy and Power Engineering, vol. 5, no. 4, pp. 350-355, 2013.

[17] O. Arpa, R. Yumrutaş, and Z. Argunhan, "Experimental investigation of the effects of diesel-like fuel obtained from waste lubrication oil on engine performance and exhaust emission," Fuel Processing Technology, vol. 91, no. 10, pp. 1241-1249, 2010. 

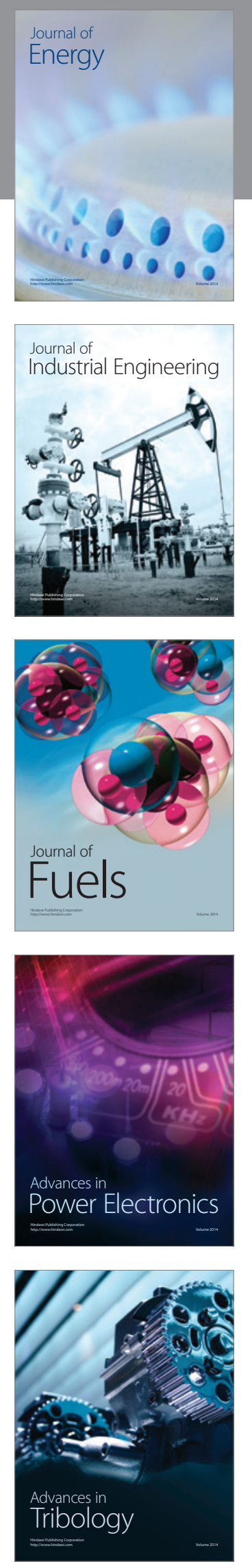
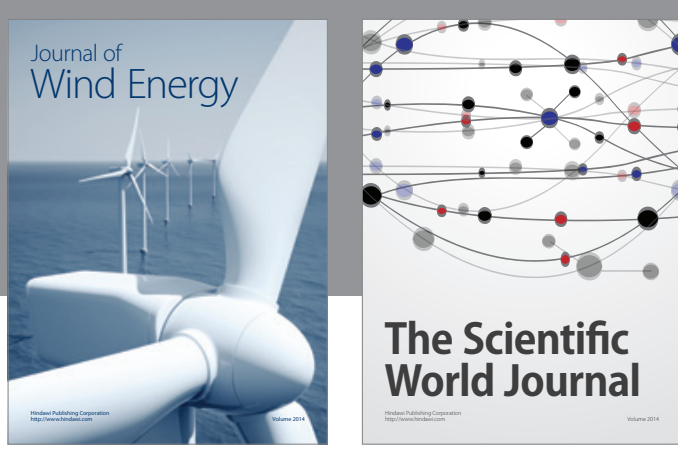

The Scientific World Journal
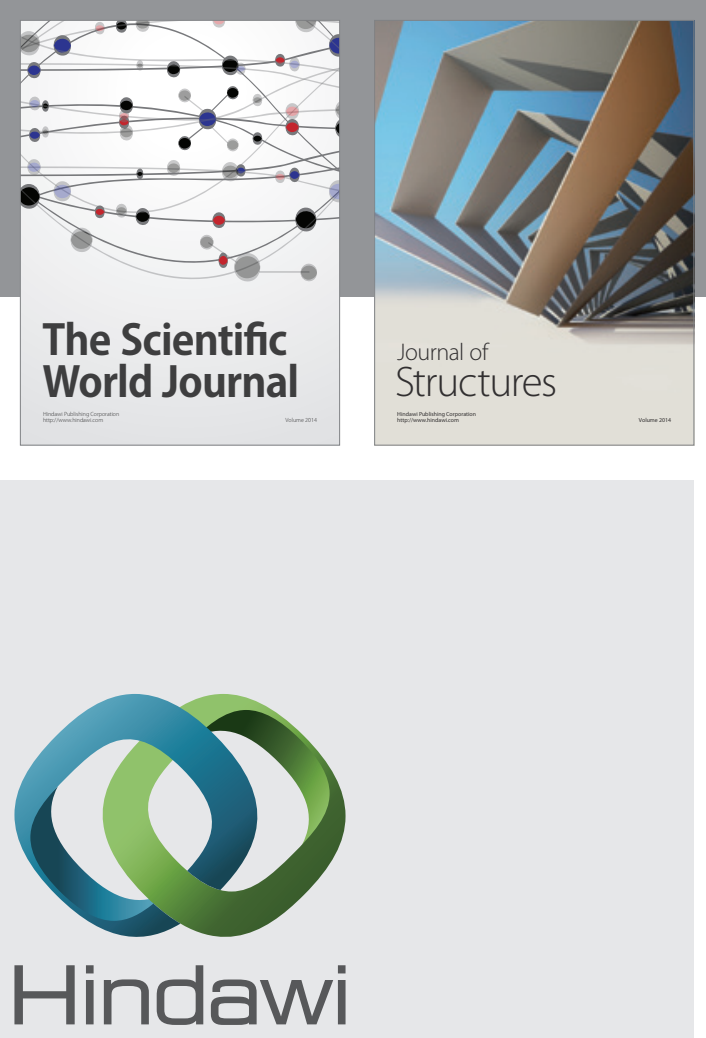

Submit your manuscripts at

http://www.hindawi.com
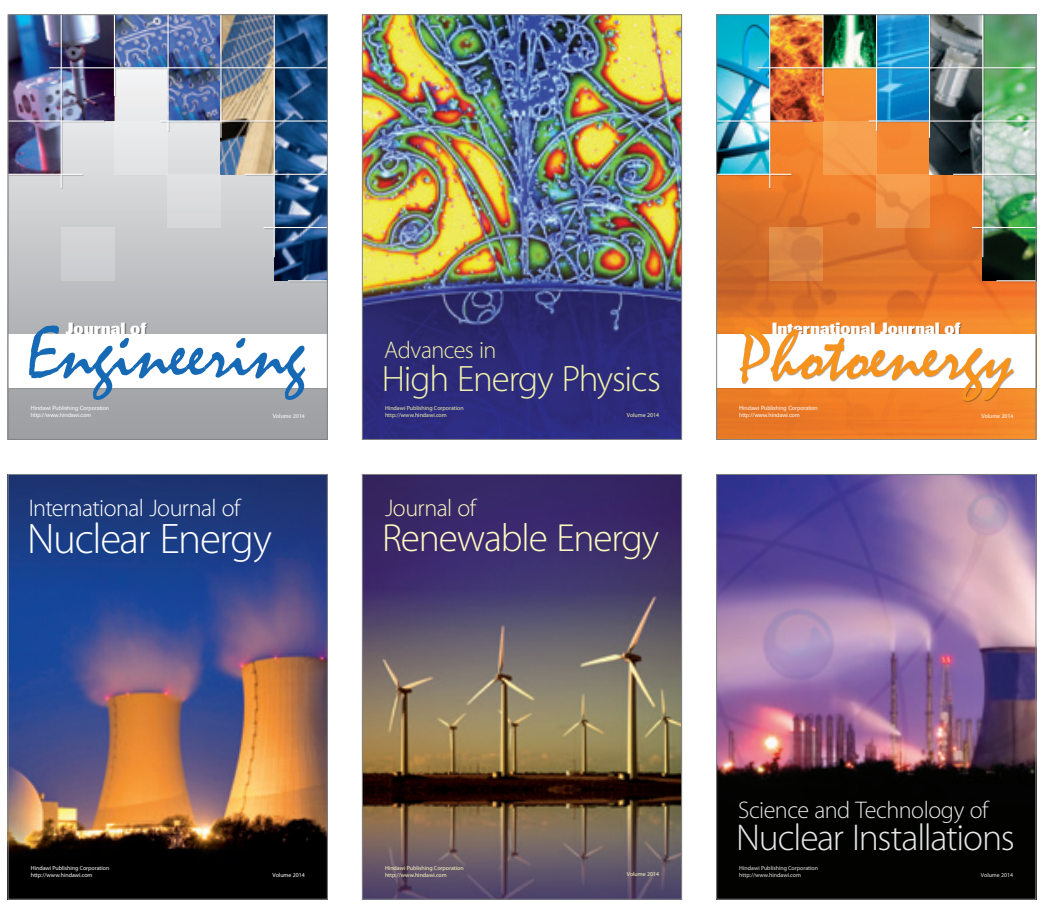
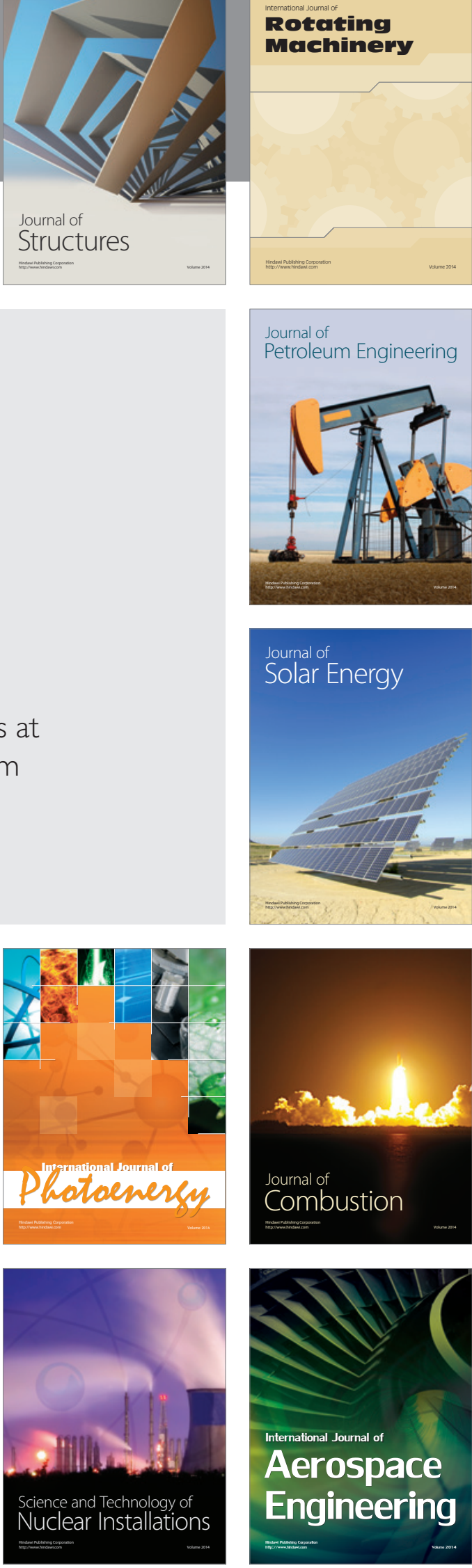